bệnh viện II Lâm Đồng"

3. Phan Mông Hoàng, Nghiêm Đức Thuân (2010), "Nghiên cứu các biến chứng và di chứng trong phẫu thuật nội soi chức năng mũi xoang tại bênh viện Củ Chi - TP.HCM", Y học thực hành, 728 (7), tr.75-77.

4. Kengo Kanai et al. Evaluation of a new and simple classification for endoscopic sinus surgery. Allergy Rhinol (Providence). 2017 Oct; 8(3): e118-e125.

5. Valentine $R$, Wormald $P J$, Sindwani $R$ Advances in absorbable biomaterials and nasal packing. Otolaryngol Clin North Am. 2009 Oct;42(5):813-28.

6. Yan M, Zheng D, Li Y, Zheng Q, Chen J, Yang B. Biodegradable nasal packings for endoscopic sinonasal surgery: a systematic review and metaanalysis. PLoS One. 2014 9(12):e115458.

7. $\mathbf{X u} \mathbf{W} 1, \mathbf{X u ~ G}, \mathbf{L i} B$, Li Y. [The application of no nasal packing after functional endoscopic sinus surgery in type I and type II chronic sinusitis]. Lin Chung Er Bi Yan Hou Tou Jing Wai Ke Za Zhi. 2012;26(24):1123-6.

\title{
TỔNG HỢP TÁC DỤNG NGOÀI TRÁNH THAI CỦA CÁC BIỆN PHÁP TRÁNH THAI
}

\section{TÓM TẮT}

Ngoài dụng cụ tử cung, các biện pháp tránh thai nội tiết đang ngày càng trở nên phổ biến không chỉ bởi hiệu quả tránh thai cao mà còn nhờ các tác dụng có lợi ngoài tránh thai. Do cơ chế hoạt động cũng như cách phân phối thuốc, các biên pháp tránh thai có hiệu quả trong điều trị một số vấn đề phụ khoa như đau bụng kinh (đăc biệt do lạc nội mạc tử cung) và cường kinh, giúp nâng cao chất lượng cuộc sống của người phụ nữ. Thuốc tránh thai cũ̃ng giúp cải thiện các bệnh lý nội khoa liên quan đến chu kỳ kinh nguyệt (đau đâu, hội chứng tiền kinh nguyết, mụn trứng cá). Các nghiên cứu cũng cho thấy tác dụng bảo vệ của thuốc tránh thai trong han chế nguy cơ một số loai ung thư đặc biệt là ung thư buồng trứng và ung thư niêm mạc tử cung. $Y$ văn cũng đề câp đến sự giảm nguy cơ ung thư niêm mạc tử cung và ung thư cổ tử cung của DCTC chứa đồng với độ tin cậy cao.

Tư khóa: Tránh thai nội tiết, dụng cụ tử cung (DCTC), tác dụng ngoài tránh thai, đau bụng kinh, ung thur.

\section{SUMMARY \\ NON-CONTRACEPTIVE EFFECTS OF CONTRACEPTION}

Besides IUD, the hormonal contraceptive methods become more and more popular because of not only high birth control effect but also non-contraceptive benefits. Due to their mechanism of action as well as delivery system, the contraceptions are successful in management of some gynecological conditions such as dysmenorrhea (especially owing to endometriosis) and menorrhagia, help to raise the standard of the women's living quality. Hormonal contraceptions also help to improve general medical conditions related to

${ }^{1}$ Bệnh viện Phụ Sản Trung Uơng

Chịu trách nhiệm chính: Nguyễn Ngọc Phương

Email: pika.hmu@gmail.com

Ngày nhận bài: 12.5.2021

Ngày phản biên khoa hoc: 2.7.2021

Ngày duyệt bài: 16.7.2021
Nguyễn Ngọc Phương1, Hà Duy Tiến ${ }^{1}$, Bùi Lê Khánh Chi ${ }^{1}$, Phùng Thị Phương Thúy ${ }^{1}$

menstrual cycles (migraines, premenstrual syndrome, acne). A reduction in ricks of some kinds of cancer, particularly ovarian and endometrial cancer is documented. Copper IUD use is associated with a decrease in cervix and endometrial cancer risk.

Keywords: hormonal contraception, Intrauterine device (IUD), non-contraceptive effect, dysmenorrhea, cancer.

\section{GIỚI THIẸU}

Các biện pháp tránh thai nội tiết và DCTC được sử dụng ngày càng rộng rãi đặc biệt là thuốc tránh thai chứa progestin tác dụng kéo dài (thuốc tiêm, que cấy, DCTC nội tiết) vì tính thuận tiện và hiệu quả tránh thai cao. Ngoài tác dụng chính là tránh thai, các biện pháp này có thể có các tác dụng phụ lên một số bệnh lý khác với vai trò dự phòng hoặc điều trị. Trong một số trường hợp, những hiệu quả đó trở thành tác dụng chính mà thuốc được sử dụng. Mục đích của bài viết này nhằm xem xét tổng quan về các các dụng ngoài tránh thai của các biện pháp tránh thai phổ biến hiện nay.

\section{CÁC THUỐC TRÁNH THAI NộI TIẾT VÀ DỤNG CỤ TỬ CUNG}

Các biên pháp tránh thai chứa nôi tiết và dụng cụ tử cung có nhiều loại chễ phẩm khác nhau (bảng 1), với các dạng trình bày, cách sử dụng và tác dụng khác nhau.

Bảng 1: Các biện pháp tránh thai nội tiêt và dụng cụ tứ cung

\begin{tabular}{|c|c|c|}
\hline \multicolumn{2}{|c|}{$\begin{array}{c}\text { Biện pháp tránh } \\
\text { thai }\end{array}$} & Chế phẩm \\
\hline \multirow{3}{*}{$\begin{array}{c}\text { Thuốc } \\
\text { tránh } \\
\text { thai } \\
\text { nội } \\
\end{array}$} & \multirow{3}{*}{$\begin{array}{l}\text { Thuốc } \\
\text { tránh thai } \\
\text { kết hợp }\end{array}$} & $\begin{array}{l}\text { Viên uống tránh thai (1pha, } \\
\text { nhiều pha, uống liên tục) }\end{array}$ \\
\hline & & Miếng dán tránh thai \\
\hline & & Vòng đặt âm đạo \\
\hline
\end{tabular}




\begin{tabular}{|c|c|c|}
\hline \multirow[t]{4}{*}{ tiết } & \multirow{4}{*}{$\begin{array}{c}\text { Thuốc } \\
\text { tránh thai } \\
\text { chỉ chứa } \\
\text { Progestin }\end{array}$} & Viên uống tránh thai \\
\hline & & Thuốc tiêm tránh thai \\
\hline & & Que cấy tránh thai \\
\hline & & DCTC chứa nội tiết \\
\hline \multicolumn{2}{|c|}{ Dụng cụ tử cung } & 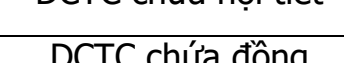 \\
\hline
\end{tabular}

2.1 Thuốc tránh thai kết hợp. Thuốc tránh thai kết hợp là sự phối hợp estrogen (thường là Ethinyl-estradiol (EE) $20-35 \mathrm{mcg}$ ) và progestin (với các thế hệ khác nhau). Hàm lượng EE thay đổi sẽ tạo ra các viên uống tránh thai nhiều pha hơn. Viên uống kết hợp thông thường dùng hằng ngày, độ dài khoảng không thuốc là 7 ngày, khi hàm lương $\mathrm{EE}$ dưới $20 \mathrm{mcg}$, khoảng thời gian này bị rút ngắn lại, do đó cần tuân thủ hướng dẫn sử dụng. Ngoài viên uống, thuốc tránh thai kết hợp còn có dạng miếng dán (Evra $($ ) ) dùng mỗi tuần, hoặc dạng vòng (Nuvaring $®$ ) đặt âm đạo trong 21 ngày.

2.2 Thuốc tránh thai chỉ chứa progestin

Thuốc tránh thai chỉ chứa progestin bao gồm viên uống (minipill), thuốc tiêm tránh thai, que cấy tránh thai và dụng cụ tử cung chứa nội tiết.

- Viên uống tránh thai chí chứa progestin. Cơ chế tránh thai chính của thuốc viên chỉ chứa progestin cổ điển (lynestrenol, levonorgestrel, ...) là làm đặc chất nhày cổ tử cung, ức chế tinh trùng xâm nhập, ngoài ra một số chế phẩm mới cũng có tác dụng ức chế phóng noãn (desogestrel,...). Hiệu quả tránh thai của thuốc phụ thuộc rất nhiều vào việc tuân thủ sử dụng vì thời gian tác dụng và bán hủy ngắn (không được muộn quá 3 giờ). So với thuốc tránh thai kếp hợp, viên uống tránh thai đơn thuần có tỷ lệ rối loạn kinh nguyệt cao hơn, tuy nhiên có thể sử dụng cho phụ nữ đang cho con bú hoă̆c người có chống chỉ định với estrogen.

- Thuốc tiêm tránh thaí. Thuốc tiêm tránh thai là một progestin tổng hợp (depot medroxyprogesterone acetate - DMPA). Thuốc có dạng tiêm bắp sâu (Depo-provera ${ }^{\circledR} 150 \mathrm{mg}$ ) hoặc tiêm dưới da (Sayana $\circledR 104 \mathrm{mg}$ ) trong 5 ngày đầu chu kỳ kinh nguyệt và nhắc lại mổi 3 tháng (12 tuần).

Nồng độ progestin cao trong huyết thanh, DMPA sẽ ức chế sự phóng noãn thông qua việc ức chế tiết gonadotropin qua đó ức chế sự tăng sinh niêm mạc tử cung.

- Que cấy tránh thai. Que cây dưới da tránh thai phổ biến hiện nay là Implanon $₫$ chứa $68 \mathrm{mg}$ etonogestrel. Sự giải phóng etonogestrel chậm, ổn định và giảm dần theo thời gian, gây ra ngăn chặn sự rụng trứng trong ít nhất 30 tháng (bằng cách ức chế đỉnh LH).

Hiệu quả tránh thai của Implanon ${ }^{\circledR}$ rất cao, tuy nhiên tác dụng có thể giảm khi dùng một số thuốc trong thời gian cấy que (chất cảm ứng enzyme, thuốc chống động kinh,...) do đó cần kết hợp một biện pháp tránh thai không nội tiết trong và sau khi dùng thuốc 1 tháng.

- Dụng cư tứ cung chứa nối tiết. DCTC Mirena ${ }^{\circledR}$ chứa $52 \mathrm{mg}$ levonorgestrel với tác dụng tránh thai khoảng 5 năm. Ngoài các cơ chế tránh thai như dụng cụ tử cung truyền thống, tác dụng của progestin làm đặc chất nhày cổ tử cung, teo tuyến niêm mạc và tăng sản xuất glycodelin $\mathrm{A}$ (chất ức chế thụ thai).

2.3 Dụng cụ tử cung. DCTC là phương pháp tránh thai tạm thời cổ điển phổ biến. Ngoài DCTC trơ (làm bằng chất dẻo polyethylen) còn có DCTC chứa hoạt chất: chứa đồng hoặc chứa nội tiết. Dụng cụ được đặt vào buồng tử cung gây phản ứng viêm tại chỗ (phản ứng dị vật), gây xơ hóa, rối loạn chế tiết ở niêm mạc tử cung dẫn đến trứng khổng làm tổ được.

DCTC chứa đồng có thêm cớ chế tránh thai do đồng gây ra phản ứng độc cho tinh trùng. Ngoài giá thành rẻ, tác dụng kéo dài, DCTC chứa đồng còn ưu điểm là dùng được cho những phụ nữ có chống chỉ định với estrogen hay progesteron, phụ nữ cho con bú hay sau sảy thai.

\section{IIICÁC TÁC DỤNG NGOÀl TRÁNH THAI}

3.1 Đau bụng kinh. Các thuốc tránh thai nội tiết giúp giảm triệu chứng đau bụng kinh. Theo Wong (2009), cơn đau bụng khi hành kinh có thể cải thiện với thuốc kết hợp (cả estrogen liều thấp và trung bình), không có sự khác biệt về các loại chế phầm. Nghiên cứu hồi cứu đa trung tâm ở Đức trên 406 phụ nữ đau bụng kinh được điều trị bằng desogestrel $75 \mathrm{mcg} /$ ngày liên tục sau 3 tháng cho thấy triệu chứng đau giảm rõ rêt và biến mất ở $93 \%$ người dùng, tỷ lệ dùng thuốc giảm đau giảm từ $70 \%$ xuống $8 \%$ [1].

Nghiên cứu của Mansour (2008) sau cấy que Implanon ${ }^{2}, 77 \%$ số phụ nữ đã hết đau bụng kinh. Đối với DCTC-levonorgestrel, triệu chứng đau giảm đáng kể, đặc biệt những trường hợp đau nặng, đây là phương pháp hiệu quả điêu trị đau bụng kinh và ít tác dụng phụ toàn thân.

3.i Rối loạn kinh nguyệt. Trên thực tế, việc định lượng máu mất trên $80 \mathrm{ml}$ (cường kinh - kinh nguyệt nhiều) đôi khi không khả thi, do đó, thời gian ra máu trên 7 ngày (rong kinh, rong huyết) hay cảm nhận ra máu nhiều ảnh hưởng đến hoạt động hằng ngày, thể chất và đời sống người phụ nữ được sử dụng làm thông số 
thay thế. Nguyên nhân ra máu nhiều có thể không được xác định ở gần một nửa số phụ nữ, một số có thể do bệnh lý phụ khoa hoặc nội khoa (giảm yếu tố đông máu).

Chưa có nghiên cứu nào về tác dụng của viên uống tránh thai đơn thuần hay que cấy tránh thai giúp giảm lượng máu kinh, mà ngược lại, các thuốc này có thể gây rong kinh.

Thuốc tránh thai kết hợp có hiệu quả giảm rong kinh cơ năng (Jensen JT, 2011) kể cả do bệnh lý nội khoa, nhưng tác dụng kém hơn DCTC-levonorgestrel (Uhm S, 2014). Các nghiên cứu đều cho thấy DCTC chứa hormon là phương pháp điều trị nội khoa hiệu quả nhất với kinh nguyệt nhiêu, không chỉ giảm ra máu mà còn cải thiện chất lượng cuộc sống và ngăn ngừa thiếu máu [2].

3.3 Lạc nội mạc tử cung. Các biện pháp tránh thai nội tiết đều có tác dụng giảm triệu chứng và sự tiến triển của LNMTC kể cả sau phẩu thuật, hiệu quả tương tự nhưng hạn chế được các tác dụng phụ của chất đồng vận $\mathrm{GnRH}$. Cơ chế tác động bao gồm giảm prostaglandin tuần hoàn, giảm phản ứng viêm và ức chế phóng noãn.

Thuốc tránh thai kết hợp dùng liên tục giúp giảm đau bụng kinh, đau bụng vùng chậu mạn tính và giảm nguy cơ tái phát sau phẫu thuật, tác dụng này giảm khi dừng thuốc (không còn hiệu quả sau 6 tháng). DCTC-levonorgestrel $52 \mathrm{mg}$ (Mirena $\circledR$ ) cũng hiệu quả trong điêu trị LNMTC không phẫu thuật và sau phẫu thuật, cùng với thuốc tránh thai kết hợp là khuyến cáo đầu tay với LNMTC có triệu chứng [3].

Các nghiên cứu cũng cho thấy hiệu quả giảm đau đáng kể với LNMTC (giảm sử dụng các thuốc giảm đau không steroid) của thuốc tiêm và thuốc cấy tránh thai, viên uống tránh thai chứa progestin tác dụng ít hơn. Các thuốc này được xem là lựa chọn thứ 2 trong điều trị LNMTC khi có chống chỉ định với estrogen [3].

3.4 U xơ tử cung. $U$ xơ tử cung là khối $u$ vùng chậu hay gặp với các triệu chứng rối loạn ra máu và đau vùng chậu. Điều trị nội khoa giứp cải thiện triệu chứng và hạn chế can thiệp phẫu thuật đặc biệt ở những phụ nữ còn nguyện vọng sinh đẻ.

Các thuốc tránh thai estrogen-progestin hoặc progestin đơn thuần đều giúp cải thiện tình trạng ra máu thông qua cơ chế làm teo niêm mạc tử cung, qua đó cải thiện hematocrit mà không làm tăng kích thước khối $u$, tuy nhiên ít tác dụng trong trường hợp u xơ tử cung to. Ngoài ra, thuốc tránh thai chỉ chứa progestin, bao gồm cá DMPA, liên quan đến giảm nguy cơ hình thành u xơ tử cung hoặc giảm thể tích tử cung sau 6 tháng điều trị. Các nghiên cứu cũng cho thấy DCTC-levonorgestrel hiệu quả hơn thuốc tránh thai kết hợp trong điêu trị u xơ tử cung [4].

3.5 Cường androgen. Mụn trứng cá và rậm lông là 2 biểu hiện của chứng cường androgen, có thể nằm trong bệnh cảnh của hội chứng buồng trứng đa nang.

Thuốc tránh thai kết hợp là lựa chọn hàng đầu trong việc kiểm soát các bất thường về kinh nguyệt và các biểu hiện da liễu của hội chứng buồng trứng đa nang. Có nhiêu cơ chế giải thích cho sự giảm androgen, đầu tiên là estrogen kích thích tổng hợp globulin liên kết hormon sinh dục tại gan, chất này gắn với các androgen tự do trong máu, làm giảm hoạt tính androgen. Ngoài ra, estrogen ức chế hormon kích thích nang trứng (FSH), progestin ức chế hormon hoàng thể hóa (LH), qua đó giảm sản xuất androgen tại buồng trứng. Hơn nữa, một số progestin (cyproterone, drosperinone, chlormadinone) có tác dụng đối kháng trên thụ thể của androgen và ức chế men 5a-reductase (chuyển testosterone thành dihydrotestosterone có hoạt tính androgen mạnh hơn).

Các nghiên cứu cho thấy hầu như các thuốc tránh thai kết hợp đều có tác dụng đối với hội chứng buồng trứng đa nang, tuy nhiên ethinylestradiol 20-35mcg hiệu quả hơn các công thức thay thế hoặc ở liều thấp hơn.

Một nghiên cứu trên Cochrane (2012) bao gồm 31 thử nghiệm lâm sàng với 12579 phụ nữ cho thấy thuốc tránh thai kết hợp làm giảm tổn thương và mức độ nghiêm trọng của mụn trứng cá so với giả dược trong 3-4 tháng [5].

Ngược lại, thuốc tránh thai chỉ chứa progestin (thuốc tiêm, que cấy) có thể là nguyên nhân gây ra mụn hoặc làm tình trạng mụn nặng hơn.

\section{6 Đau đâu và triệu chứng tiên kinh} nguyệt. Đau đầu hoăcc đau nửa đầu (migrain) có thể xuất hiện khi hành kinh do sự sụt giảm đột ngột của các hormon buồng trứng, đặc biệt là estrogen. Đau nửa đầu (migrain) biểu hiện đau từ trung bình đến nặng, có thể kèm theo buồn nôn, rối loạn thị lực, rối loạn cảm giác, ngôn ngữ... (triệu chứng não khu trú thoáng qua - Aura) xảy ra trước hoặc trong cơn đau đâu.

Hội chứng tiền kinh nguyệt bao gồm các triệu chứng về thể chất (phù, căng ngực, mệt mỏi, ... đặc biệt là đau đâuu) hoặc các rối loạn tâm thần (mất ngủ, cáu gắt, trầm cảm, ...) xảy ra trước khi hành kinh vài ngày đến 2 tuần và thường kết thúc sau khi có kinh vài ngày. Các nghiên cứu cho thấy, ngoài các điều trị triệu chứng đặc hiệu, 
thuốc tránh thai kết hợp giúp cải thiện hội chứng tiền kinh nguyệt.

Các thuốc tránh thai nội tiết dùng liên tục đều có hiệu quả trong dự phòng và điều trị đau đầu trong hoặc trước kinh nguyệt trừ trường hợp đau đầu có aura bị chống chỉ định với estrogen [6].

3.7 Ung thư. Các biện pháp tránh thai (tránh thai kết hợp, DCTC) giúp giảm nguy cơ một số loại ung thư, đặc biệt là ung thư buồng trứng và ung thư niêm mạc tử cung.

- Ung thư buồng trứng. Các nghiên cứu đều cho thãy nguy cơ ung thư buồng trứng giảm đáng kể ở phụ nữ sử dụng thuốc tránh thai kết hợp, nguy cơ càng giảm khi dùng thuốc kéo dài và sử dụng trước 35 tuổi, tác dụng đến hơn 20 năm sau khi dừng thuốc. Cơ chễ chưa rõ ràng nhưng người ta cho rằng thuốc tránh thai kết hợp ức chế rụng trứng, ngăn sự hao mòn do rụng trứng lặp lại, ngoài ra thuốc cũng làm giảm tiếp xúc của buồng trứng với mức độ cao của các gonadotropin tuyến yên ảnh hưởng đến sinh lý tế bào biểu mô buồng trứng, việc giảm mất kinh góp phần giảm sự vận chuyển ngược dòng các yếu tố gây u qua ống dẫn trứng và cuối cùng là tác động trực tiếp đến quá trình chết tự nhiên của tế bảo biểu mô buồng trứng trong các tổn thương tiền ung thư' [7].

- Ung thư niêm mạc tử cung. Thuốc tránh thai nội tiết có thể giảm nguy cơ xuất hiện ung thư niêm mạc tử cung, đặc biệt là DCTClevonorgestrel giúp giảm $78 \%$, DCTClevonorgestrel cũng hiệu quả trong điều trị quá sản lành tính niêm mạc tử cung. Thuốc tránh thai kết hợp cũng có hiệu quả này nhưng ít hơn, việc sử dụng thuốc kéo dài có thể giảm $34 \%$ nguy cơ ung thư niêm mạc tử cung. Các tác dụng bảo vệ này có thể thấy ở cả nhóm bệnh nhân nguy cơ cao mắc ung thư niêm mạc tử cung như béo phì, hút thuốc,... [8].

Ngoài ra, dù cơ chế chưa rõ ràng nhưng một số nghiên cứu cũng cho thãy hiệu quả bảo vệ của DCTC chứa đồng với ung thư niêm mạc tử cung [3].

- Mốt số ung thư khác. Một số nghiên cứu cho thấy thuốc tránh thai kết hợp có thể giảm nguy cơ cung thư đại trực tràng tới $40 \%$, do làm thay đổi quá trình tổng hợp và bài tiết mật, dẫn đến giảm nồng độ axit mật trong đại tràng, giả thuyết khác là estrogen ức chế sự phát triển các tế bào ung thư ở đại tràng khi người ta xác định được các thụ thể của nó trên biểu mô đại tràng bình thường và tân sinh.

Nghiên cứu tổng hợp và phân tích gộp của Cortessis (2017) cho thấy tỷ lệ ung thư cổ tử cung ít hơn ở nhóm phụ nữ dùng DCTC chứa đồng [9]. Tuy nhiên, tác dung bảo vệ này chỉ làm giảm nguy cơ ung thư cổ tử cung chứ không liên quan đến nguy cơ nhiễm HPV, dù vậy vẫn chưa đủ bằng chứng để khuyến cáo dùng DCTC dự phòng ung thư cổ tử cung [3].

Ngoài ra, một số nghiên cứu cũng cho thấy lợi ích của các thuốc tránh thai nội tiết trong việc giảm nguy cơ với các ung thư vú, thận, bàng quang, tụy và ung thư bạch huyết [10].

\section{KẾT LUÂ̂N}

Ngoài tác dụng tránh thai, nhiều tác dụng ngoài tránh thai của thuốc tránh thai nội tiết và DCTC cũng được ghi nhận, đó là hiệu quả trong điều trị các bệnh lý: đau bụng kinh, cường kinh, lạc nội mạc tử cung, mụn trứng cá, các triệu chứng tiền kinh nguyệt, cũng như trong dự phòng một số ung thư như ung thư buồng trứng và ung thư niêm mạc tử cung.

\section{TÀI LIẸU THAM KHẢO}

1. C. L. Wong, C. Farquhar, H. Roberts và cộng sư (2009). Oral contraceptive pill for primary dysmenorrhoea. Cochrane Database Syst Rev, 2009 (4), Cd002120.

2. S. Uhm và L. Perriera (2014). Hormonal contraception as treatment for heavy menstrual bleeding: a systematic review. Clin Obstet Gynecol, 57 (4), 694-717.

3. L. Amat, A. Bulach, M. Leclercq và cộng sự (2018). [Additional non-contraceptive effects of contraception: CNGOF Contraception Guidelines]. Gynecol Obstet Fertil Senol, 46 (12), 883-888.

4. G. S. Sohn và S. Cho (2018). Current medical treatment of uterine fibroids. 61 (2), 192-201.

5. A. O. Arowojolu, M. F. Gallo, L. M. Lopez và công sự (2012). Combined oral contraceptive pills for treatment of acne. Cochrane Database Syst Rev, (7), Cd004425.

6. A. L. Altshuler, M. E. Gaffield và J. N. Kiarie (2015). The WHO's medical eligibility criteria for contraceptive use: 20 years of global guidance. Curr Opin Obstet Gynecol, 27 (6), 451-459.

7. L. Iversen, S. Fielding, Ø. Lidegaard và công sư (2018). Association between contemporary hormonal contraception and ovarian cancer in women of reproductive age in Denmark: prospective, nationwide cohort study. Bmj, 362, k3609.

8. K. A. Michels, R. M. Pfeiffer, L. A. Brinton và công sự (2018). Modification of the Associations Between Duration of Oral Contraceptive Use and Ovarian, Endometrial, Breast, and Colorectal Cancers. JAMA Oncology, 4 (4), 516-521.

9. v. K. Cortessis, M. Barrett, N. Brown Wade và cộng sư (2017). Intrauterine Device Use and Cervical "Cancer Risk: A Systematic Review and Meta-analysis. Obstet Gynecol, 130 (6), 1226-1236.

10. K. A. Michels, L. A. Brinton, R. M. Pfeiffer và công sư (2018). Oral Contraceptive Use and Risks of "Cancer in the NIH-AARP Diet and Health Study. American journal of epidemiology, 187 (8), 1630-1641. 